\title{
Downregulation of Oxidative and Nitrosative Apoptotic Signaling by L-Carnitine in Ifosfamide-Induced Fanconi Syndrome Rat Model
}

\author{
Mohamed M. Sayed-Ahmed, Mohamed M. Hafez, Meshan Lafi Aldelemy, \\ Abdulaziz M. Aleisa, Salem S. Al-Rejaie, Khaled A. Al-Hosaini, Naif O. Al-Harbi, \\ Mohamed M. Al-Harbi, and Othman A. Al-Shabanah
}

Department of Pharmacology and Toxicology, College of Pharmacy, King Saud University, P.O. Box 2457, Riyadh 11451, Saudi Arabia

Correspondence should be addressed to Othman A. Al-Shabanah, shabanah@ksu.edu.sa

Received 16 June 2012; Accepted 19 October 2012

Academic Editor: Francisco Javier Romero

Copyright ( 2012 Mohamed M. Sayed-Ahmed et al. This is an open access article distributed under the Creative Commons Attribution License, which permits unrestricted use, distribution, and reproduction in any medium, provided the original work is properly cited.

\begin{abstract}
It is well documented that ifosfamide (IFO) therapy is associated with sever nephropathy in the form of Fanconi syndrome. Although oxidative stress has been reported as a major player in IFO-induced Fanconi syndrome, no mechanism for this effect has been ascertained. Therefore, this study has been initiated to investigate, on gene expression level, the mechanism of IFO-induce nephrotoxicity and those whereby carnitine supplementation attenuates this serious side effect of IFO. To achieve the ultimate goals of this study, adult male rats were assigned to one of four treatment groups, namely, control, L-carnitine, IFO, and IFO plus L-carnitine. Administration of IFO for 5 days significantly increased serum creatinine, blood urea nitrogen (BUN), and total nitrate/nitrite (NOx) production in kidney tissues. In addition, IFO significantly increased mRNA expression of inducible nitric oxide synthase (iNOS), caspase-9, and caspase-3 and significantly decreased expression of glutathione peroxides (GPx), catalase (CAT), and Bcl2 in kidney tissues. Administration of L-carnitine to IFO-treated rats resulted in a complete reversal of the all biochemical and gene expression changes, induced by IFO, to the control values. Data from this study suggest that L-carnitine prevents the development of IFO-induced nephrotoxicity via downregulation of oxidative and nitrosative apoptotic signaling in kidney tissues.
\end{abstract}

\section{Introduction}

Ifosfamide (IFO) is an oxazaphosphorine nitrogen mustard alkylating agent which is used in most cancer chemotherapy and immunosuppressive protocols [1-3]. Nevertheless, high therapeutic doses of IFO are associated with sever nephrotoxicity in the form of Fanconi syndrome especially in children $[4,5]$. IFO is oxidized by hepatic cytochrome P450 to IFO mustard which is responsible for its antitumour activity [6]. On the other hand, more than $50 \%$ of IFO doses undergo side chain dealkylation to the inactive metabolites 2- and 3-dechloroethylifosfamide and equimolar amounts of the highly toxic metabolites chloroacetaldehyde (CAA) and thiodiglycolic acid (TDGA) $[7,8]$. It is well documented that local formation and accumulation of CAA and TDGA in human kidney are the major player in IFO-induced nephropathy $[7,9]$. Hence, despite the coadministration of mesna which has low reactivity with CAA, treatment with IFO is associated with severe proximal tubular dysfunction in the form of fanconi syndrome [10]. This syndrome is a generalized dysfunction of the proximal tubule and is characterized by excessive urinary excretion of glucose, phosphate, bicarbonate, amino acids, and other solutes excreted by this segment of the nephron $[10,11]$.

Nitric oxide (NO) is mediator and regulator of inflammatory responses and its overproduction triggers many diseases as malignancy, rheumatoid arthritis, and organ toxicity [12-15]. The effect of NO depends on the production site, nitric oxide synthase (NOS), duration of action, and level of reactive oxygen intermediates present. In kidney, NO 


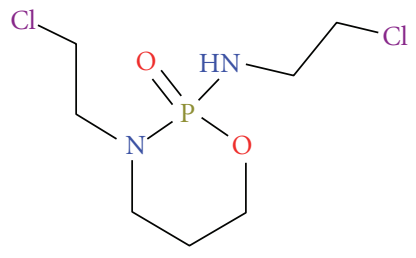

Figure 1: Chemical structure of ifosfamide. $\mathrm{C}_{7} \mathrm{H}_{15} \mathrm{Cl}_{2} \mathrm{~N}_{2} \mathrm{O}_{2} \mathrm{P}$ MW. 261.09.

mediates many physiologic functions and plays an important role in nephrotoxicity pathogenesis [16]. NO is generated by three isoforms of NOS (the neuronal, endothelial, and inducible). In normal kidney tissues, inducible NOS (iNOS) is induced by cytokines and its activity elevates $\mathrm{NO}$ level which is responsible for cell death $[17,18]$. Expression of iNOS increased in glomerular infiltrating macrophages or mesangial cells of nephrotoxic nephritis [19]. Endothelial NOS (eNOS) is expressed in endothelial cells of renal and glomeruli and plays a role in intrarenal vascular tone by direct relaxation of afferent arteriole [20]. Neuronal NO (nNOS) is expressed in macula densa and plays a role in regulation of tubule-glomerular response [21, 22].

L-carnitine, an endogenous mitochondrial membrane compound, is derived from two sources: endogenous synthesis in liver and kidney and from exogenous dietary sources for instance red meat and dairy products [23, 24]. The main physiological function of L-carnitine is facilitating longchain fatty acids transport into mitochondria for entering $\beta$ oxidation cycle and energy production [25]. Although recent studies have reported that L-carnitine attenuates cyclophosphamide and IFO-induced renal metabolic damage, no mechanism for this effect has been ascertained. Therefore, the current study has been initiated to investigate, on gene expression level, the mechanism of IFO-induced nephrotoxicity and those whereby carnitine supplementation attenuates this serious side effect of IFO.

\section{Material and Methods}

Holoxan vials (Baxter oncology GmbH, Germany) contains $1 \mathrm{~g}$ IFO in a dry lyophilized powder form. The content of each vial was freshly dissolved in sterile water immediately before injection. The chemical structure of IFO is shown in Figure 1. L-carnitine was kindly supplied by Dr. Zaven Orfalian, Sigma-Tau Pharmaceuticals, Pomezia, Roma, Italy. It was freshly dissolved in normal saline prior to injection. Primers used in this study were purchased from Metabion International AG (Germany). All other chemicals used were of highest analytical grade.

2.1. Animals. Adult male Wistar albino rats, weighing 180 $200 \mathrm{~g}$, were obtained from the Animal Care Center, College of Pharmacy, King Saud University, Saudi Arabia and were housed in under controlled environmental conditions $\left(25^{\circ} \mathrm{C}\right.$ and a $12 \mathrm{~h}$ light/dark cycle) with free access to pulverized standard food and tap water. The protocol of this study has been approved by Research Ethics Committee of College of Pharmacy, King Saud University.

2.2. Experimental Design. A total of 40 rats were divided randomly into 4 groups of 10 animals each. Group 1 (control group) were intraperitoneally (i.p.) injected with normal saline $(2.5 \mathrm{~mL} / \mathrm{kg} /$ day $)$ for 10 successive days. Group 2 (carnitine-supplemented group) were given L-carnitine ( $200 \mathrm{mg} / \mathrm{kg} /$ day, i.p.) for 10 successive days [26]. Group 3 (IFO group) received normal saline for 5 successive days followed by IFO $(50 \mathrm{mg} / \mathrm{kg} /$ day, i.p.) for 5 successive days [27]. Group 4 (IFO-carnitine-supplemented rats) received the same doses of L-carnitine as group 2 for 5 days before and 5 days concomitant with IFO (50 mg/kg/day, i.p.) [26]. Immediately after the last dose of treatment, animals were sacrificed by decapitation after exposure to ether in desiccator kept in a well-functioning hood and blood samples were obtained. Serum was separated for measurement of creatinine and blood urea nitrogen (BUN). Both kidneys were quickly excised and kept in $-80^{\circ} \mathrm{C}$ for measuring nitric oxide production and mRNA expression of GPx, CAT, Bcl2, caspase-9, caspase-3, iNOS, eNOS, and nNOS.

\subsection{Methods}

\subsubsection{Quantification of mRNA Expression by Real-Time Poly- merase Chain Reaction}

Total RNA Extraction. Total RNA were extracted from kidney tissues by Trizol method as previously described [28]. In brief, RNA was extracted by homogenization in TRIzol reagent (Invitrogen, life technology, USA). The homogenate was incubated for $5 \mathrm{~min}$ at room temperature. Chloroform was added, and vortexes and subjected to centrifugation. The aqueous phase was isolated and the total RNA was precipitated by ethanol. After centrifugation and washing the total RNA was finally eluted in diethyl pyrocarbonate-treated $\mathrm{H}_{2} \mathrm{O}$. The quantity was characterized using a UV spectrophotometer (NanoDrop 8000, Thermo Scientific, USA). The isolated RNA has an A 260/280 ratio of 1.9-2.1.

First-Strand cDNA. First-strand cDNA was synthesized from $5 \mu \mathrm{g}$ of total RNA by reverse transcription with a SuperScript first-strand synthesis kit (Invitrogen, life technology, USA), according to the manufacturer's instructions.

Real-Time Polymerase Chain Reaction. Real-time PCR was performed using KAPA FAST qPCR kit master mix (KAPA Biosysems, USA) and $2^{-\Delta \Delta C t}$ method. GAPDH gene was used as the endogenous control. PCR assay was optimized by varying the PCR conditions such as the concentration of cDNA, primers concentration, amplification cycle number, and annealing temperature. Briefly, a standard $25 \mu \mathrm{L}$ reaction mixture contained in final concentration of $1 \times$ KAPA SYBER qPCR master mix buffer, $0.3 \mu \mathrm{M}$ of each forward and reverse primers, for GPx, CAT, iNOS, nNOS, eNOS, caspase-9, caspase-3, Bcl2, and GAPDH (Table 1), 100 ng of cDNA and RNase, DNase free water. The reaction was done in an ABI 
TABLE 1: Sequences of oligonucleotide primers for quantitative real-time PCR.

\begin{tabular}{lll}
\hline Gene name & Forward & Reverse \\
\hline iNOS & CCCTTCCGAAGTTTCTGGCAGCAGC & GGGTGTCAGAGTCTTGTGCCTTTGG \\
eNOS & GGGCTCCCTCCTTCCGGCTGCACC & GGATCCCTGGAAAAGGCGGTGAGG \\
nNOS & CTGTGACAACTCTCGATACAACATC & GAGTCTATAGTTGAGCATCTCCTGG \\
Caspase-9 & TCACGGCTTTGATGGAGATG & AGAGAGGATGACCACCACGAA \\
Caspase-3 & AAATTCAAGGGACGGGTCATG & GAGCTTGTGCGTACAGTT \\
Bcl2 & AGAGGGGCTACGAGTGGGAT & CTCAGTCATCCACAGGGCGA \\
GPx & CGGTTTCCCGTGCAATCAGT & ACACCGGGGACCAAATGATG \\
Catalase & CGACCGAGGGATTCCAGATG & ATCCGGGTCTTCCTGTGCAA \\
GAPDH & AACTCCCATTCCTCCACCTT & GAGGGCCTCTCTCTTGCTCT \\
\hline
\end{tabular}

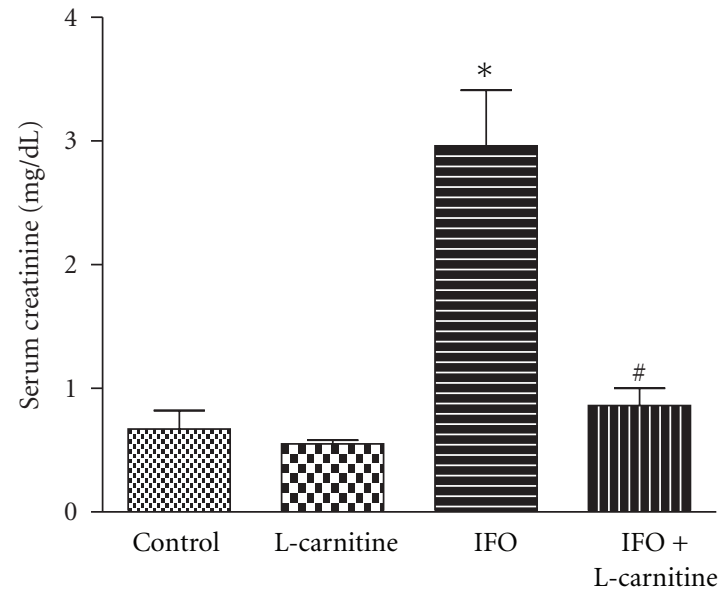

(a)

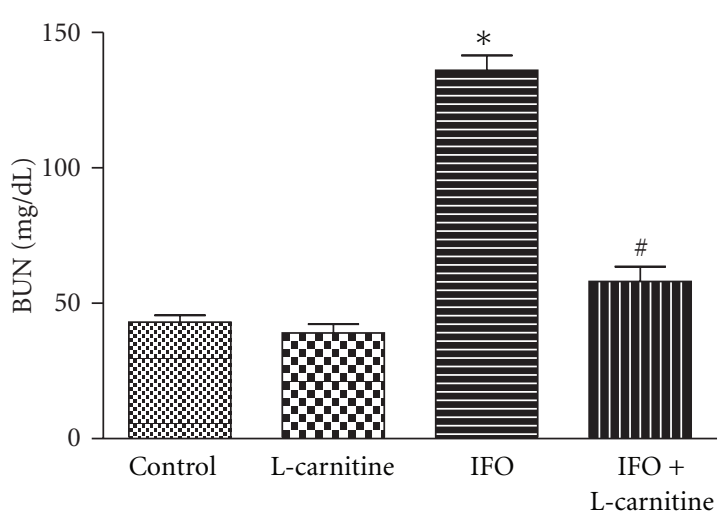

(b)

FIGURE 2: Effects of ifosfamide (IFO), L-carnitine, and their combination on serum creatinine (a) and BUN (b). Rats were randomly divided into 4 different groups of 10 animals each: control, L-carnitine, IFO, and IFO-carnitine supplemented. Carnitine supplementation was induced in rats by daily intraperitoneal injection of L-carnitine $(200 \mathrm{mg} / \mathrm{kg} / \mathrm{day})$ for 10 successive days. IFO nephrotoxicity was induced in rats by administration of IFO $(50 \mathrm{mg} / \mathrm{kg} / \mathrm{day}$, IP) for 5 successive days. IFO-carnitine-supplemented rats were given the same doses of L-carnitine $(200 \mathrm{mg} / \mathrm{kg} /$ day $)$ for 5 days before and 5 days concomitant with IFO $(50 \mathrm{mg} / \mathrm{kg} /$ day, IP). At the end of the treatment protocol, serum creatinine and BUN were measured. Data are presented as mean \pm S.E.M. $(n=10)$. ${ }^{*}$ and ${ }^{\#}$ indicate significant change from control and IFO, respectively, at $P<0.05$ using ANOVA followed by Tukey-Kramer as a post-ANOVA test.

96-Well Optical Reaction Plate placed on ice before cDNA template was added. The standard thermal cycling conditions of initial $50^{\circ} \mathrm{C}$ for $2 \mathrm{~min}$ and $95^{\circ} \mathrm{C}$ for $10 \mathrm{~min}$ followed by 40 cycles at $95^{\circ} \mathrm{C}$ for $15 \mathrm{sec}$ and $60^{\circ} \mathrm{C}$ for $1 \mathrm{~min}$ were used. All reactions were performed using an ABI 7500 System (Applied Biosystem, life technology, USA). Experiments were performed in triplicates for all data points. Each $\mathrm{qPCR}$ reaction included no-template controls.

\subsubsection{Determination of Total Nitrate/Nitrite Concentrations} in Kidney Tissues Homogenates. Total nitrate/nitrite (NOx), an index of nitric oxide (NO) production, was measured as the stable end-product nitrite according to the method of Miranda et al. [29]. This assay is based on the reduction of nitrate by vanadium trichloride combined with detection by the acidic Griess reaction. The diazotization of sulphanilic acid with nitrite at acidic $\mathrm{pH}$ and subsequent coupling with $N$-(10 naphthyl)-ethylenediamine produced an intensely colored product that is measured spectrophotometrically at $540 \mathrm{~nm}$. Levels of $\mathrm{NOx}$ were expressed as $\mathrm{mmol} / \mathrm{g}$ wet tissue.

2.3.3. Assessment of Serum Blood Urea Nitrogen and Creatinine. Blood urea nitrogen and serum creatinine concentrations were measured spectrophotometrically according to the methods of Tabacco et al. [30] and Fabiny and Ertingshausen [31], respectively.

2.4. Statistical Analysis. Differences between obtained values (mean \pm SEM, $n=10$ ) were carried out by one way analysis of variance (ANOVA) followed by the Tukey-Kramer multiple comparison test. $P \leq 0.05$ was taken as a criterion for a statistically significant difference.

\section{Results}

Figure 2 shows the effect of IFO, L-carnitine, and their combination on serum nephrotoxicity indices. Administration 


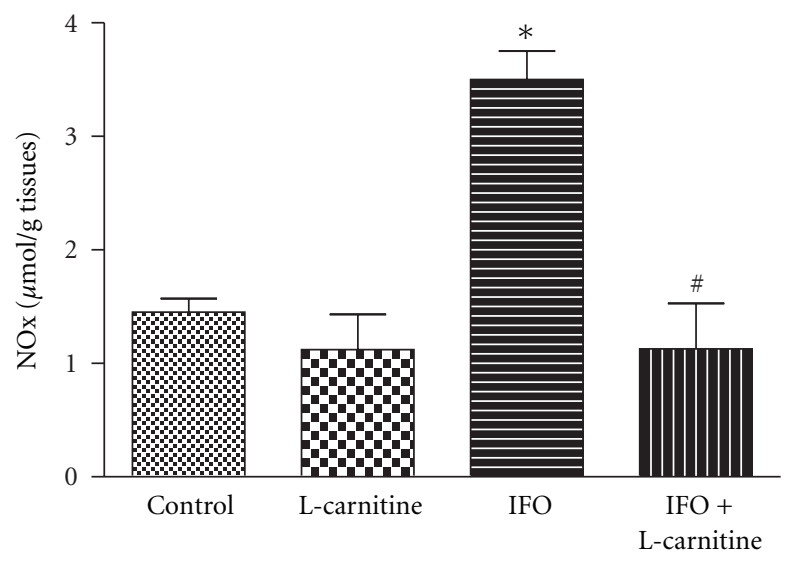

FIGURE 3: Effects of ifosfamide (IFO), L-carnitine, and their combination on NOx production in kidney tissues. Rats were randomly divided into 4 different groups of 10 animals each: control, L-carnitine, IFO, and IFO-carnitine supplemented. Carnitine supplementation was induced in rats by daily intraperitoneal injection of L-carnitine $(200 \mathrm{mg} / \mathrm{kg} / \mathrm{day})$ for 10 successive days. IFO nephrotoxicity was induced in rats by administration of IFO ( $50 \mathrm{mg} / \mathrm{kg} / \mathrm{day}$, IP) for 5 successive days. IFO-carnitine supplemented rats were given the same doses of L-carnitine $(200 \mathrm{mg} / \mathrm{kg} /$ day $)$ for 5 days before and 5 days concomitant with IFO $(50 \mathrm{mg} / \mathrm{kg} / \mathrm{day}$, IP $)$. At the end of the treatment protocol, NOx level was measured in kidney tissues. Data are presented as mean \pm S.E.M. $(n=10) .{ }^{*}$ and ${ }^{\#}$ indicate significant change from control and IFO, respectively, at $P<0.05$ using ANOVA followed by Tukey-Kramer as a post-ANOVA test.

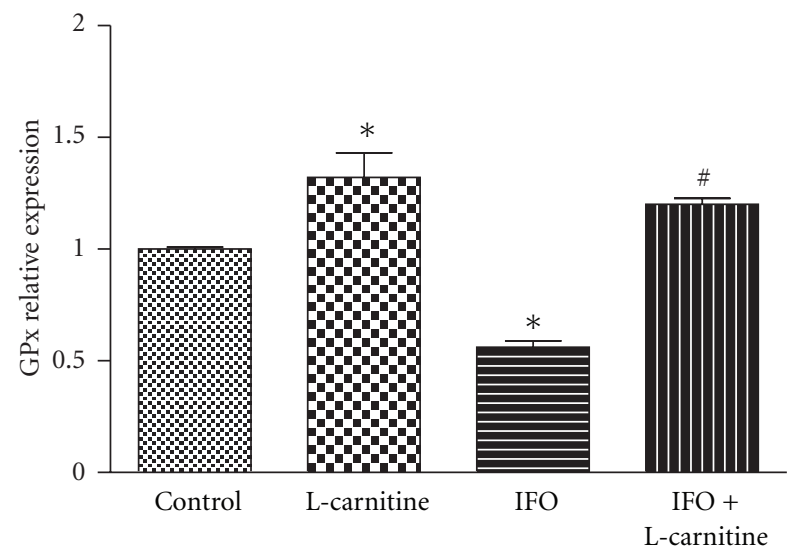

(a)

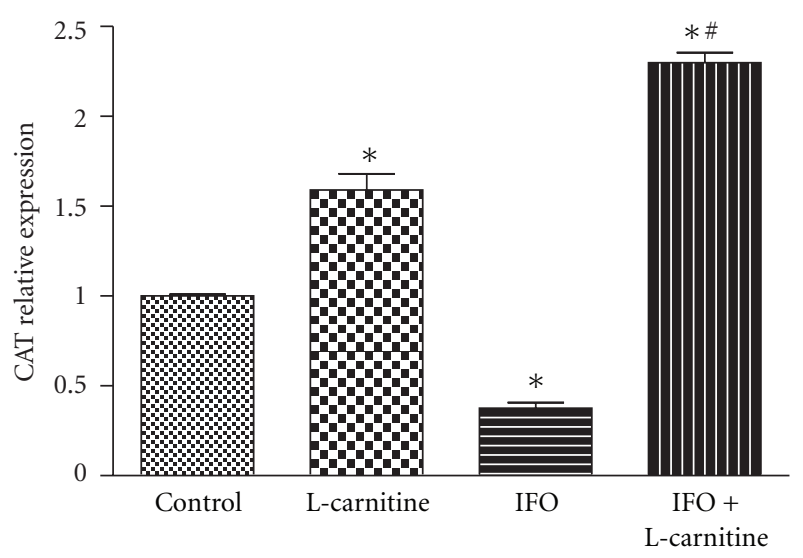

(b)

FIGURE 4: Effects of ifosfamide (IFO), L-carnitine, and their combination on mRNA expression of GPx (a) and CAT (b) in rat kidney tissues. Rats were randomly divided into 4 different groups of 10 animals each: control, L-carnitine, IFO, and IFO-carnitine supplemented. Carnitine supplementation was induced in rats by daily intraperitoneal injection of L-carnitine ( $200 \mathrm{mg} / \mathrm{kg} /$ day) for $10 \mathrm{successive}$ days. IFO nephrotoxicity was induced in rats by administration of IFO $(50 \mathrm{mg} / \mathrm{kg} / \mathrm{day}$, IP) for 5 successive days. IFO-carnitine supplemented rats were given the same doses of L-carnitine $(200 \mathrm{mg} / \mathrm{kg} /$ day) for 5 days before and 5 days concomitant with IFO ( $50 \mathrm{mg} / \mathrm{kg} / \mathrm{day}$, IP). At the end of the treatment protocol, expressions levels of GPx and CAT were measured in kidney tissues. Data are presented as mean \pm S.E.M. $(n=10)$. ${ }^{*}$ and " indicate significant change from control and IFO, respectively, at $P<0.05$ using ANOVA followed by Tukey-Kramer as a post-ANOVA test.

of IFO alone showed a significant $342 \%(P<0.001)$ and $216 \%(P<0.001)$, increase in serum creatinine and BUN, respectively, compared to the control group. Interestingly, administration of L-carnitine with IFO resulted in complete reversal of IFO-induced increase in serum creatinine and BUN to the control values. On the other hand, administration of L-carnitine alone resulted in nonsignificant change in serum creatinine and BUN.

Figure 3 shows the effects of IFO, L-carnitine, and their combination on the level of $\mathrm{NOx}$ in kidney tissue. IFO resulted in a significant $146 \%$ increase in NOx production in kidney tissues $(P<0.001)$, whereas, L-carnitine alone resulted in non-significant change. Combination of Lcarnitine with IFO decreased the level of NOx production by IFO in kidney tissue to control values.

To investigate the effect of IFO on oxidative stress genes, the expression levels of GPx and CAT were measured in kidney tissues using RT-PCR Figure 4. IFO alone significantly decreased the expression of GPx (a) and CAT (b) mRNA in kidney tissues by $44 \%(P<0.05)$ and $63 \%(P<$ $0.001)$, respectively, compared to control group. However, administration of L-carnitine to IFO-treated rats completely 


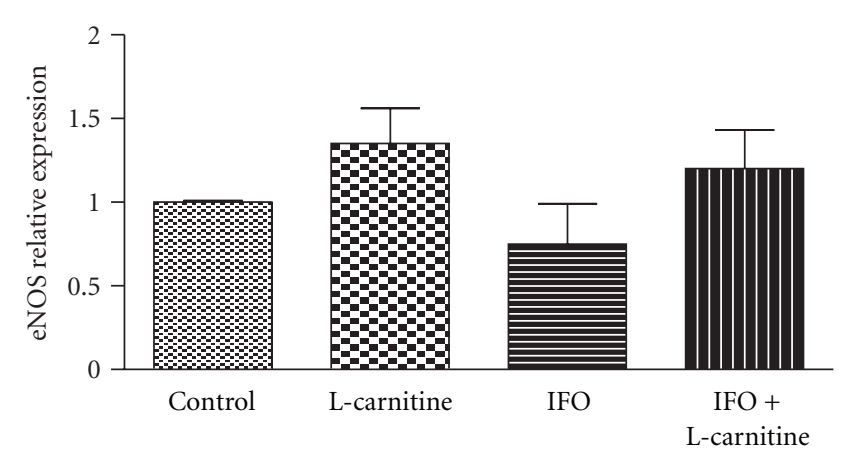

(a)

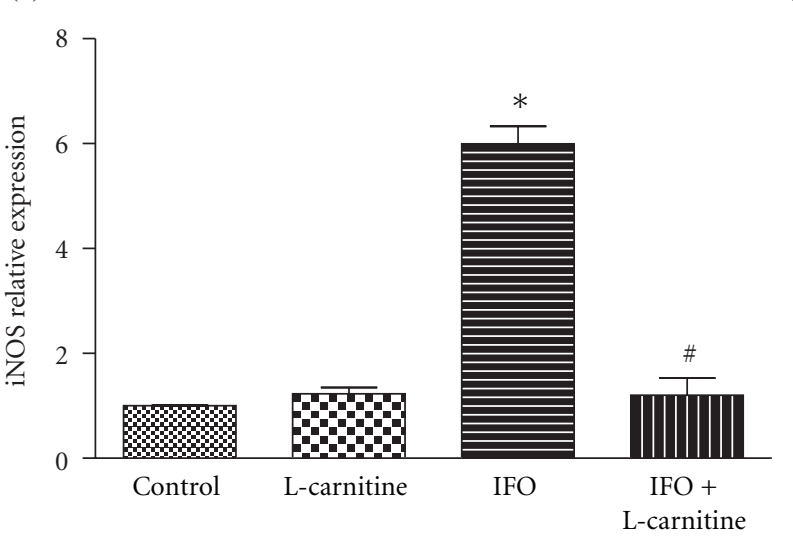

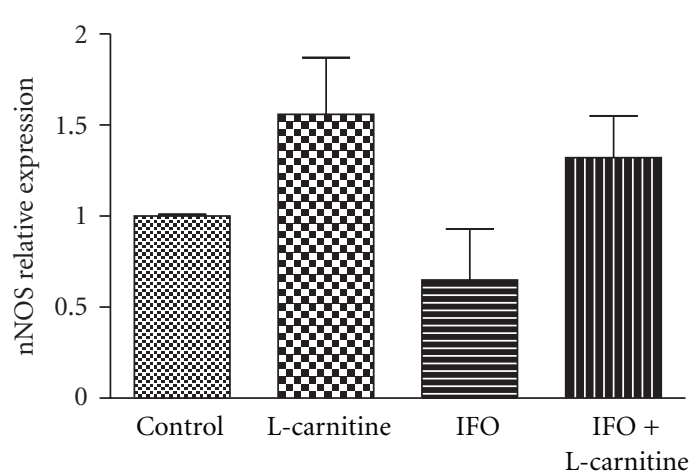

(b)

(c)

Figure 5: Effects of ifosfamide (IFO), L-carnitine, and their combination on mRNA expression of eNOS (a), nNOS (b), and iNOS (c) in rat kidney tissues. Rats were randomly divided into 4 different groups of 10 animals each: control, L-carnitine, IFO, and IFOcarnitine supplemented. Carnitine supplementation was induced in rats by daily intraperitoneal injection of L-carnitine (200 mg/kg/day) for 10 successive days. IFO nephrotoxicity was induced in rats by administration of IFO ( $50 \mathrm{mg} / \mathrm{kg} / \mathrm{day}$, IP) for 5 successive days. IFOcarnitine supplemented rats were given the same doses of L-carnitine $(200 \mathrm{mg} / \mathrm{kg} /$ day $)$ for 5 days before and 5 days concomitant with IFO $(50 \mathrm{mg} / \mathrm{kg} / \mathrm{day}, \mathrm{IP})$. At the end of the treatment protocol, expressions levels of eNOS, nNOS, and iNOS were measured in kidney tissues. Data are presented as mean \pm S.E.M. $(n=10){ }^{*}$ and ${ }^{\#}$ indicate significant change from control and IFO, respectively, at $P<0.05$ using ANOVA followed by Tukey-Kramer as a post-ANOVA test.

normalized the decrease in antioxidant enzymes to control values.

Figure 5 shows the effect IFO, LC, and their combination on mRNA expression of NOS isoforms including eNOS (a), nNOS (b), and iNOS (c) in kidney tissues using RTPCR analysis. IFO alone resulted in non-significant change in the expression of eNOS and nNOS mRNA in kidney tissues as compared to the control rats. On the other hand, the expression level of iNOS mRNA was significantly increased by 6 -fold in IFO-treated rats compared to control. Interestingly, L-carnitine in combination with IFO resulted in complete reversal of IFO-induced increase in iNOS level in kidney tissue to the control values.

Figure 6 shows the effect IFO, LC, and their combination on mRNA expression of caspase- 9 (a), caspase-3 (b), and $\mathrm{Bcl} 2$ (c) in kidney tissue. IFO resulted in a significant increase in the expression of caspase- 9 and caspase- 3 by 6 and 8 fold, respectively, compared to control group $(P<0.001)$. In contrast, IFO significantly decreased the expression levels of $\mathrm{Bcl} 2$ by 0.35 -fold compared to control group. However, administration of L-carnitine to IFO-treated rats completely normalized IFO-induced increase in caspase- 9 and caspase- 3 and decrease in $\mathrm{Bcl} 2$ expression to control values.

\section{Discussion}

Renal toxicity is reported in 5\% of IFO-treated patients in the form of Fanconi syndrome [27, 32-34]. This syndrome is characterized by renal glucosuria, loss of electrolytes, bicarbonate and lactate, generalized hyperaminoaciduria and low-molecular-weight proteinuria [35]. Several mechanisms for IFO-induced nephrotoxicity have been reported including oxidative stress, depletion of glutathione, and inhibition of endocytosis in renal tubular proximal cells $[36,37]$. In the current study, IFO nephrotoxicity was evidenced by increasing serum creatinine and BUN. Under similar experimental condition, earlier and recent studies have reported that administration of IFO $(50 \mathrm{mg} / \mathrm{kg})$ for 5 consecutive days is associated with severe nephrotoxicity in the form of fanconi syndrome $[11,27,38]$.

Nitric oxide is produced in kidney from L-arginine by the action of NOS isoforms and played a key role in maintaining 


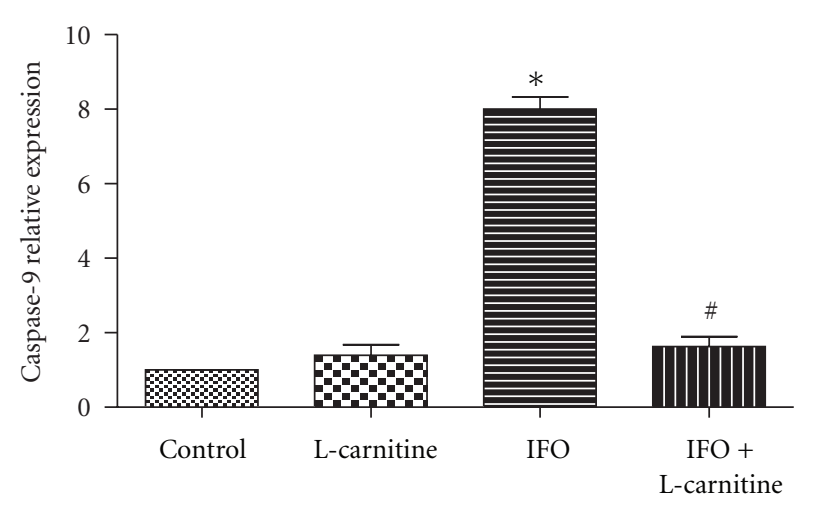

(a)

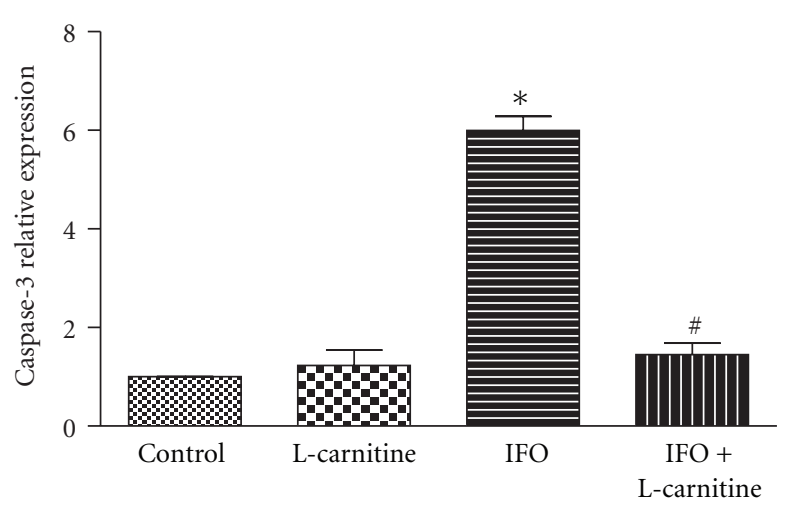

(b)

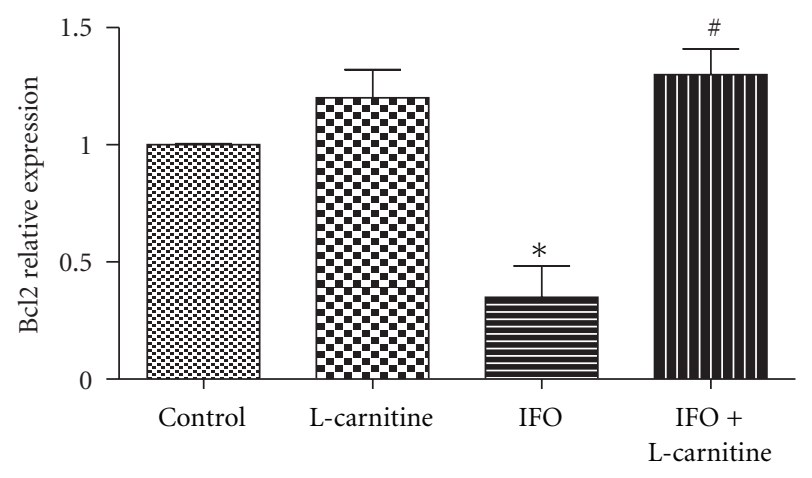

(c)

Figure 6: Effects of ifosfamide (IFO), L-carnitine and their combination on mRNA expression of Caspase9 (a), Caspase3 (b) and Bcl2 (c) in rat kidney tissues. Rats were randomly divided into 4 different groups of 10 animals each: Control, L-carnitine, IFO, and IFOcarnitine supplemented. Carnitine supplementation was induced in rats by daily intraperitoneal injection of L-carnitine (200 mg/kg/day) for 10 successive days. IFO nephrotoxicity was induced in rats by administration of IFO ( $50 \mathrm{mg} / \mathrm{kg} /$ day, I.P.) for 5 successive days. IFOcarnitine supplemented rats were given the same doses of L-carnitine $(200 \mathrm{mg} / \mathrm{kg} /$ day $)$ for 5 days before and 5 days concomitant with IFO $(50 \mathrm{mg} / \mathrm{kg} / \mathrm{day}$, I.P.). At the end of the treatment protocol, expressions levels of Caspase9, Caspase3 and Bcl 2 were measured in kidney tissues. Data are presented as mean \pm S.E.M. $(n=10) .{ }^{*}$ and ${ }^{\#}$ indicate significant change from control and IFO, respectively, at $P<0.05$ using ANOVA followed by Tukey-Kramer as a post-ANOVA test.

vascular tone. In nephrotoxicity, the increase in NOx production after IFO administration could be a secondary event following the increase in inducible nitric oxide synthase $[39,40]$. Our study showed similar correlation in which the increase in NOx production accompanied with iNOS increase expression level after IFO administration. These results suggest that the $\mathrm{NO}$ production contributes to the pathogenesis of IFO-induced nephrotoxicity. Low levels of NO synthesized by the constitutive enzymes, eNOS and nNOS, are involved in normal physiological conditions, whereas high levels of NO produced by iNOS have a role primarily in pathological processes induced by cytokines and oxidative stress $[41,42]$. Furthermore, NO inhibits the ability of cells to repair damaged DNA by inhibiting DNA repair proteins [43]. In addition, the excess production of NO by iNOS plays an important role in many pathological processes, such as inflammation and carcinogenesis [44]. In the present study, the expression of eNOS and nNOS were decreased in IFO-treated rat. The selective downregulation of eNOS and nNOS may play a role in decreasing medullary blood flow and secondary tissue injury. Administration of
L-carnitine in combination with IFO normalized NOx and gene expression of iNOS. Similar result was showed that L-carnitine administration normalized the serum and renal lipid alterations as well as gene expression of iNOS [45].

Damage, at the cellular level by oxidants, is attenuated by antioxidant enzyme such as GPx and CAT [46]. Catalase and GPx catalyze dismutation of superoxide anion $\left(\mathrm{O}_{2}{ }^{-}\right)$ into hydrogen peroxide $\left(\mathrm{H}_{2} \mathrm{O}_{2}\right)$ which then converting $\mathrm{H}_{2} \mathrm{O}_{2}$ to water thus providing protection against reactive oxygen species [47]. The reduction in activity of these enzymes may be caused by the increase in free radical production during IFO metabolism $[48,49]$. Our study showed decrease in the gene expression levels of GPx and CAT in kidney tissue of IFO-treated rats. Therefore, IFO not only increased the free radical formation in kidney tissues, but also decreased its ability to detoxify reactive oxygen species. For that reason, IFO-administrated rat kidneys are more susceptible to ROS damage due to the deficiency in antioxidant defense enzyme. Data from this study revealed that L-carnitine administration in combination with IFO significantly increased antioxidant enzyme. The increase in GSH level leads to increase in 
GPx activity in which the former acts as a cofactor for later [50]. Our results are consistent with previous studies reported that L-carnitine had similar nonenzymatic freeradical scavenging and antilipid peroxidation activities [51, 52].

Caspases are family of cell death proteases that play an essential role in the execution phase of apoptosis [53]. Activation of caspases 3,8 , and 9 occurs early after IFO treatment of renal epithelial cells and inhibition of caspase activity suppresses IFO-induced cell death [54]. Our results showed that IFO treatment induces renal cell apoptosis by increasing expression level of both caspase- 3 and caspase- 9 and decreasing $\mathrm{Bcl} 2$. The mitochondrial apoptotic pathways are caspasedependent and caspase-independent pathways. Caspase-3 and cytochrome c play important roles in caspase-dependent pathway. Under this condition, IFO can activate Bax and Bak leading to cytochrome c release from mitochondria and subsequent caspase activity. The present data show that the vital role of caspase- 3 and -9 in the apoptotic cascade leading to IFO-induced cell death. Similarly, Schwartz and his colleague found that caspase-9 plays an important role in the apoptotic cascade leading to cyclophosphamide-induced cell death [55]. L-carnitine supplementation in combination with IFO resulted in increase $\mathrm{Bcl} 2$ gene expression level which act as inhibitor for caspase- 3 and -9 genes expressions by blocking mitochondrial release of cytochrome c [56].

\section{Conclusion}

Data from the present study suggest that L-carnitine prevents the development of IFO-induced Fanconi syndrome via downregulation of oxidative and nitrosative apoptotic signaling in kidney tissues.

\section{Conflict of Interests}

All authors declare that there is no conflict of interests.

\section{Acknowledgment}

Authors extend their appreciation to the Deanship of Scientific Research at King Saud University for funding this work through the research group Project no. RGP-VPP-142.

\section{References}

[1] Y. Alici-Evcimen and W. S. Breitbart, "Ifosfamide neuropsychiatric toxicity in patients with cancer," Psycho-Oncology, vol. 16, no. 10, pp. 956-960, 2007.

[2] B. Ames, L. D. Lewis, S. Chaffee, J. Kim, and R. Morse, "Ifosfamide-induced encephalopathy and movement disorder," Pediatric Blood and Cancer, vol. 54, no. 4, pp. 624-626, 2010.

[3] K. L. Dechant, R. N. Brogden, T. Pilkington, and D. Faulds, "Ifosfamide/Mesna. A review of its antineoplastic activity, pharmacokinetic properties and therapeutic efficacy in cancer," Drugs, vol. 42, no. 3, pp. 428-467, 1991.

[4] R. Rossi, A. Godde, A. Kleinebrand et al., "Unilateral nephrectomy and cisplatin as risk factors of ifosfamide- induced neph- rotoxicity: analysis of 120 patients," Journal of Clinical Oncology, vol. 12, no. 1, pp. 159-165, 1994.

[5] R. Skinner, I. M. Sharkey, A. D. J. Pearson, and A. W. Craft, "Ifosfamide, mesna, and nephrotoxicity in children," Journal of Clinical Oncology, vol. 11, no. 1, pp. 173-190, 1993.

[6] F. Yu, J. Megyesi, and P. M. Price, "Cytoplasmic initiation of cisplatin cytotoxicity," American Journal of Physiology, vol. 295, no. 1, pp. F44-F52, 2008.

[7] T. M. Visarius, H. Bähler, A. Küpfer, T. Cerny, and B. H. Lauterburg, "Thiodiglycolic acid is excreted by humans receiving ifosfamide and inhibits mitochondrial function in rats," Drug Metabolism and Disposition, vol. 26, no. 3, pp. 193-196, 1998.

[8] G. Sangster, S. B. Kaye, K. C. Calman, and J. F. Dalton, "Failure of 2-mercaptoethane sulphonate sodium (mesna) to protect against ifosfamide nephrotoxicity," European Journal of Cancer and Clinical Oncology, vol. 20, no. 3, pp. 435-436, 1984.

[9] I. Nissim, O. Horyn, Y. Daikhin et al., "Ifosfamide-induced nephrotoxicity: mechanism and prevention," Cancer Research, vol. 66, no. 15, pp. 7824-7831, 2006.

[10] M. P. Goren, R. K. Wright, M. E. Horowitz, and C. B. Pratt, "Ifosfamide-induced subclinical tubular nephrotoxicity despite mesna," Cancer Treatment Reports, vol. 71, no. 2, pp. 127-130, 1987.

[11] I. Nissim and J. M. Weinberg, "Glycine attenuates Fanconi syndrome induced by maleate or ifosfamide in rats," Kidney International, vol. 49, no. 3, pp. 684-695, 1996.

[12] R. Korhonen, A. Lahti, H. Kankaanranta, and E. Moilanen, "Nitric oxide production and signaling in inflammation," Current Drug Targets, vol. 4, no. 4, pp. 471-479, 2005.

[13] R. M. J. Palmer, D. D. Rees, D. S. Ashton, and S. Moncada, "L-arginine is the physiological precursor for the formation of nitric oxide in endothelium-dependent relaxation," Biochemical and Biophysical Research Communications, vol. 153, no. 3, pp. 1251-1256, 1988.

[14] C. Nathan and Q. W. Xie, "Nitric oxide synthases: roles, tolls, and controls," Cell, vol. 78, no. 6, pp. 915-918, 1994.

[15] R. K. Kanwar, N. Singh, S. Gurudevan, and J. R. Kanwar, "Targeting hepatitis B virus and human papillomavirus induced carcinogenesis: novel patented therapeutics," Recent Patents on Anti-Infective Drug Discovery, vol. 6, no. 2, pp. 158-174, 2011.

[16] D. Ogawa, K. Shikata, M. Matsuda et al., "Protective effect of a novel and selective inhibitor of inducible nitric oxide synthase on experimental crescentic glomerulonephritis in WKY rats," Nephrology Dialysis Transplantation, vol. 17, no. 12, pp. 21172121, 2002.

[17] H. Mühl, K. Sandau, B. Brüne, V. A. Briner, and J. Pfeilschifter, "Nitric oxide donors induce apoptosis in glomerular mesangial cells, epithelial cells and endothelial cells," European Journal of Pharmacology, vol. 317, no. 1, pp. 137-149, 1996.

[18] M. K. Mohaupt, J. L. Elzie, K. Y. Ahn, W. L. Clapp, C. S. Wilcox, and B. C. Kone, "Differential expression and induction of mRNAs encoding two inducible nitric oxide synthases in rat kidney," Kidney International, vol. 46, no. 3, pp. 653-665, 1994.

[19] V. Cattell, T. Cook, and S. Moncada, "Glomeruli synthesize nitrite in experimental nephrotoxic nephritis," Kidney International, vol. 38, no. 6, pp. 1056-1060, 1990.

[20] C. Teupe, S. Richter, B. Fisslthaler et al., "Vascular gene transfer of phosphomimetic endothelial nitric oxide synthase (S1177D) using ultrasound-enhanced destruction of plasmidloaded microbubbles improves vasoreactivity," Circulation, vol. 105, no. 9, pp. 1104-1109, 2002.

[21] E. Brunelli, I. Perrotta, E. Talarico, and S. Tripepi, "Localization of two nitric oxide synthase isoforms, eNOS and iNOS, 
in the skin of Triturus italicus (Amphibia, Urodela) during development," Comparative Biochemistry and Physiology, vol. 142, no. 2, pp. 249-255, 2005.

[22] Y. Chiba, T. Arimoto, T. Yoshikawa, and M. Misawa, "Elevated nitric oxide synthase activity concurrent with antigeninduced airway hyperresponsiveness in rats," Experimental Lung Research, vol. 26, no. 7, pp. 535-549, 2000.

[23] E. Arrigoni-Martelli and V. Caso, "Carnitine protects mitochondria and removes toxic acyls from xenobiotics," Drugs under Experimental and Clinical Research, vol. 27, no. 1, pp. 27-49, 2001.

[24] W. Lysiak, K. Lilly, F. DiLisa, P. P. Toth, and L. L. Bieber, "Quantitation of the effect of L-carnitine on the levels of acidsoluble short-chain acyl-CoA and CoASH in rat heart and liver mitochondria," Journal of Biological Chemistry, vol. 263, no. 3, pp. 1151-1156, 1988.

[25] C. J. Rebouche and H. Seim, "Carnitine metabolism and its regulation in microorganisms and mammals," Annual Review of Nutrition, vol. 18, pp. 39-61, 1998.

[26] M. M. Sayed-Ahmed, "L-Carnitine attenuates ifosfamideinduced carnitine deficiency and decreased intramitochondrial CoA-SH in rat kidney tissues," Journal of Nephrology, vol. 24, no. 4, pp. 490-498, 2011.

[27] M. M. Sayed-Ahmed, A. Q. Darweesh, and A. J. Fatani, "Carnitine deficiency and oxidative stress provoke cardiotoxicity in an ifosfamide-induced Fanconi Syndrome rat model," Oxidative Medicine and Cellular Longevity, vol. 3, no. 4, pp. 266-274, 2010.

[28] P. Chomczynski, "A reagent for the single-step simultaneous isolation of RNA, DNA and proteins from cell and tissue samples," BioTechniques, vol. 15, no. 3, pp. 532-537, 1993.

[29] K. M. Miranda, M. G. Espey, and D. A. Wink, "A rapid, simple spectrophotometric method for simultaneous detection of nitrate and nitrite," Nitric Oxide, vol. 5, no. 1, pp. 62-71, 2001.

[30] A. Tabacco, F. Meiattini, E. Moda, and P. Tarli, "Simplified enzymic/colorimetric serum urea nitrogen determination," Clinical Chemistry, vol. 25, no. 2, pp. 336-337, 1979.

[31] D. L. Fabiny and G. Ertingshausen, "Automated reactionrate method for determination of serum creatinine with the CentrifiChem," Clinical Chemistry, vol. 17, no. 8, pp. 696-700, 1971.

[32] C. B. Pratt, W. H. Meyer, J. J. Jenkins et al., "Ifosfamide, Fanconi's syndrome, and rickets," Journal of Clinical Oncology, vol. 9, no. 8, pp. 1495-1499, 1991.

[33] J. De Schepper, G. Stevens, M. Verboven, C. Baeta, and J. Otten, "Ifosfamide-induced Fanconi's syndrome with growth failure in a 2-year-old child," American Journal of Pediatric Hematology/Oncology, vol. 13, no. 1, pp. 39-41, 1991.

[34] A. Suarez, H. McDowell, P. Niaudet, E. Comoy, and F. Flamant, "Long-term follow-up of ifosfamide renal toxicity in children treated for malignant mesenchymal tumors: an International Society of Pediatric Oncology Report," Journal of Clinical Oncology, vol. 9, no. 12, pp. 2177-2182, 1991.

[35] J. Drube, E. Schiffer, H. Mischak et al., "Urinary proteome pattern in children with renal Fanconi syndrome," Nephrology Dialysis Transplantation, vol. 24, no. 7, pp. 2161-2169, 2009.

[36] O. A. Badary, "Thymoquinone attenuates ifosfamide-induced Fanconi syndrome in rats and enhances its antitumor activity in mice," Journal of Ethnopharmacology, vol. 67, no. 2, pp. 135142, 1999.

[37] Z. Yaseen, C. Michoudet, G. Baverel, and L. Dubourg, "Mechanisms of the ifosfamide-induced inhibition of endocytosis in the rat proximal kidney tubule," Archives of Toxicology, vol. 82, no. 9, pp. 607-614, 2008.
[38] O. Sehirli, A. Sakarcan, A. Velioglu-Ogunc et al., "Resveratrol improves ifosfamide-induced Fanconi syndrome in rats," Toxicology and Applied Pharmacology, vol. 222, no. 1, pp. 33$41,2007$.

[39] K. K. Son and K. J. Hall, "Nitric oxide-mediated tumor cell killing of cisplatin-based interferon- $\gamma$ gene therapy in murine ovarian carcinoma," Cancer Gene Therapy, vol. 7, no. 10, pp. 1324-1328, 2000.

[40] K. Son and Y. M. Kim, "In vivo cisplatin-exposed macrophages increase immunostimulant-induced nitric oxide synthesis for tumor cell killing," Cancer Research, vol. 55, no. 23, pp. 55245527, 1995.

[41] G. Julou-Schaeffer, G. A. Gray, I. Fleming, C. Schott, J. R. Parratt, and J. C. Stoclet, "Loss of vascular responsiveness induced by endotoxin involves L-arginine pathway," American Journal of Physiology, vol. 259, no. 4, pp. H1038-H1043, 1990.

[42] E. D. Franke, C. M. Lucas, and E. San Roman, "Antibody response of humans to the circumsporozoite protein of Plasmodium vivax," Infection and Immunity, vol. 59, no. 8, pp. 2836-2838, 1991.

[43] D. A. Wink, J. A. Cook, D. Christodoulou et al., "Nitric oxide and some nitric oxide donor compounds enhance the cytotoxicity of cisplatin," Nitric Oxide, vol. 1, no. 1, pp. 88-94, 1997.

[44] H. Ohshima and H. Bartsch, "Chronic infections and inflammatory processes as cancer risk factors: possible role of nitric oxide in carcinogenesis," Mutation Research, vol. 305, no. 2, pp. 253-264, 1994.

[45] M. H. Mahfouz and E. K. Mohamed, "Effects of L-carnitine on inducible nitric oxide synthase, insulin like growth factor1 gene expression and insulin receptor substrate-1 in kidney tissues of insulin resistant rats induced by high fructose feeding," Egyptian Journal of Biochemistry and Molecular Biology, vol. 29, no. 2, 2011.

[46] A. Koc, M. Duru, H. Ciralik, R. Akcan, and S. Sogut, "Protective agent, erdosteine, against cisplatin-induced hepatic oxidant injury in rats," Molecular and Cellular Biochemistry, vol. 278, no. 1-2, pp. 79-84, 2005.

[47] M. M. Sayed-Ahmed, A. M. Aleisa, S. S. Al-Rejaie et al., "Thymoquinone attenuates diethylnitrosamine induction of hepatic carcinogenesis through antioxidant signaling," Oxidative Medicine and Cellular Longevity, vol. 3, no. 4, pp. 254-261, 2010.

[48] E. D. Brookins Danz, J. Skramsted, N. Henry, J. A. Bennett, and R. S. Keller, "Resveratrol prevents doxorubicin cardiotoxicity through mitochondrial stabilization and the Sirtl pathway," Free Radical Biology and Medicine, vol. 46, no. 12, pp. 15891597, 2009.

[49] K. Fisher-Wellman, H. K. Bell, and R. J. Bloomer, "Oxidative stress and antioxidant defense mechanisms linked to exercise during cardiopulmonary and metabolic disorders," Oxidative Medicine and Cellular Longevity, vol. 2, no. 1, pp. 43-51, 2009.

[50] L. P. James, P. R. Mayeux, and J. A. Hinson, "Acetaminopheninduced hepatotoxicity," Drug Metabolism and Disposition, vol. 31, no. 12, pp. 1499-1506, 2003.

[51] A. Arduini, "Carnitine and its acyl esters as secondary antioxidants? [9]," American Heart Journal, vol. 123, no. 6, pp. 1726-1727, 1992.

[52] M. M. Sayed-Ahmed, M. M. Khattab, M. Z. Gad, and N. Mostafa, "L-carnitine prevents the progression of atherosclerotic lesions in hypercholesterolaemic rabbits," Pharmacological Research, vol. 44, no. 3, pp. 235-242, 2001.

[53] N. A. Thornberry and Y. Lazebnik, "Caspases: enemies within,” Science, vol. 281, no. 5381, pp. 1312-1316, 1998. 
[54] R. Becker, A. Ritter, U. Eichhorn et al., "Induction of DNA breaks and apoptosis in crosslink-hypersensitive V79 cells by the cytostatic drug $\beta$-D-glucosyl-ifosfamide mustard," British Journal of Cancer, vol. 86, no. 1, pp. 130-135, 2002.

[55] P. S. Schwartz and D. J. Waxman, "Cyclophosphamide induces caspase 9-dependent apoptosis in 9L tumor cells," Molecular Pharmacology, vol. 60, no. 6, pp. 1268-1279, 2001.

[56] J. M. Adams and S. Cory, "The Bcl-2 protein family: arbiters of cell survival," Science, vol. 281, no. 5381, pp. 1322-1326, 1998. 


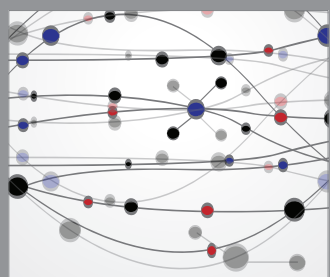

The Scientific World Journal
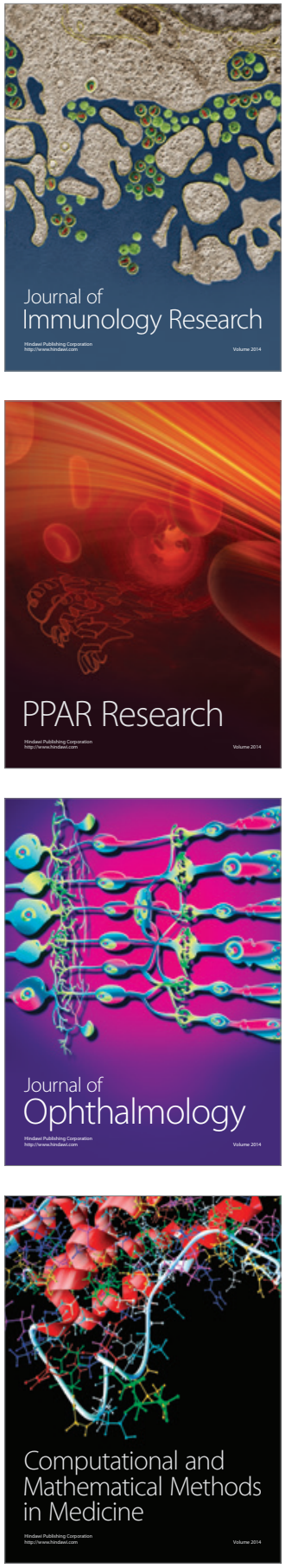

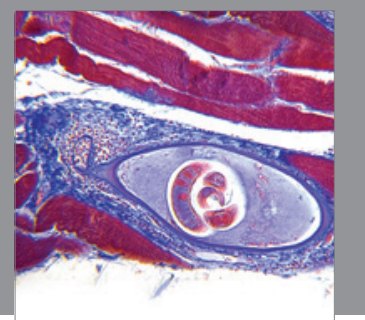

Gastroenterology

Research and Practice
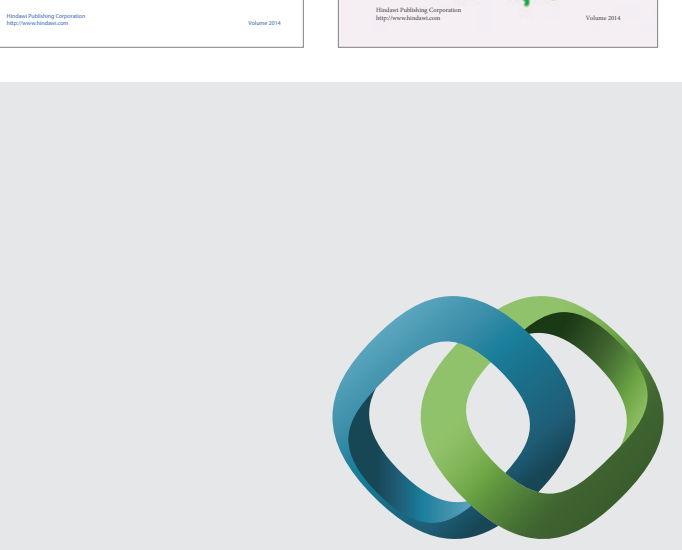

\section{Hindawi}

Submit your manuscripts at

http://www.hindawi.com
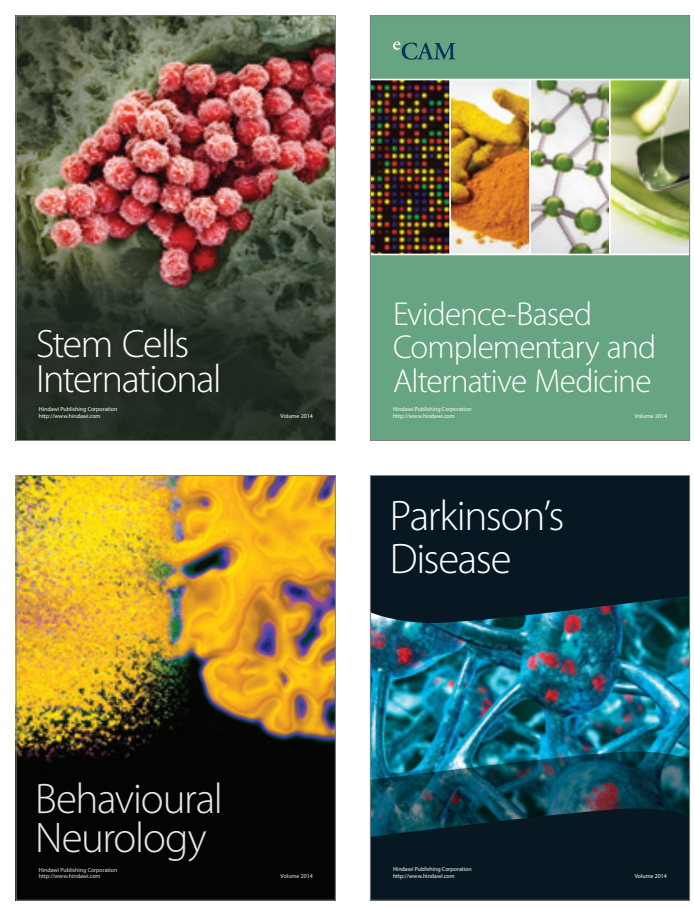

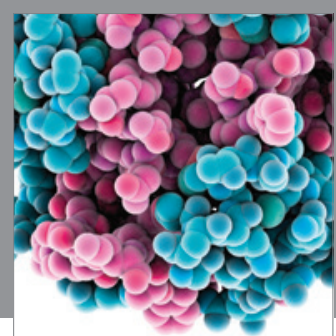

Journal of
Diabetes Research

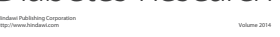

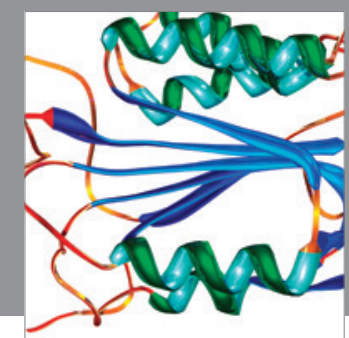

Disease Markers
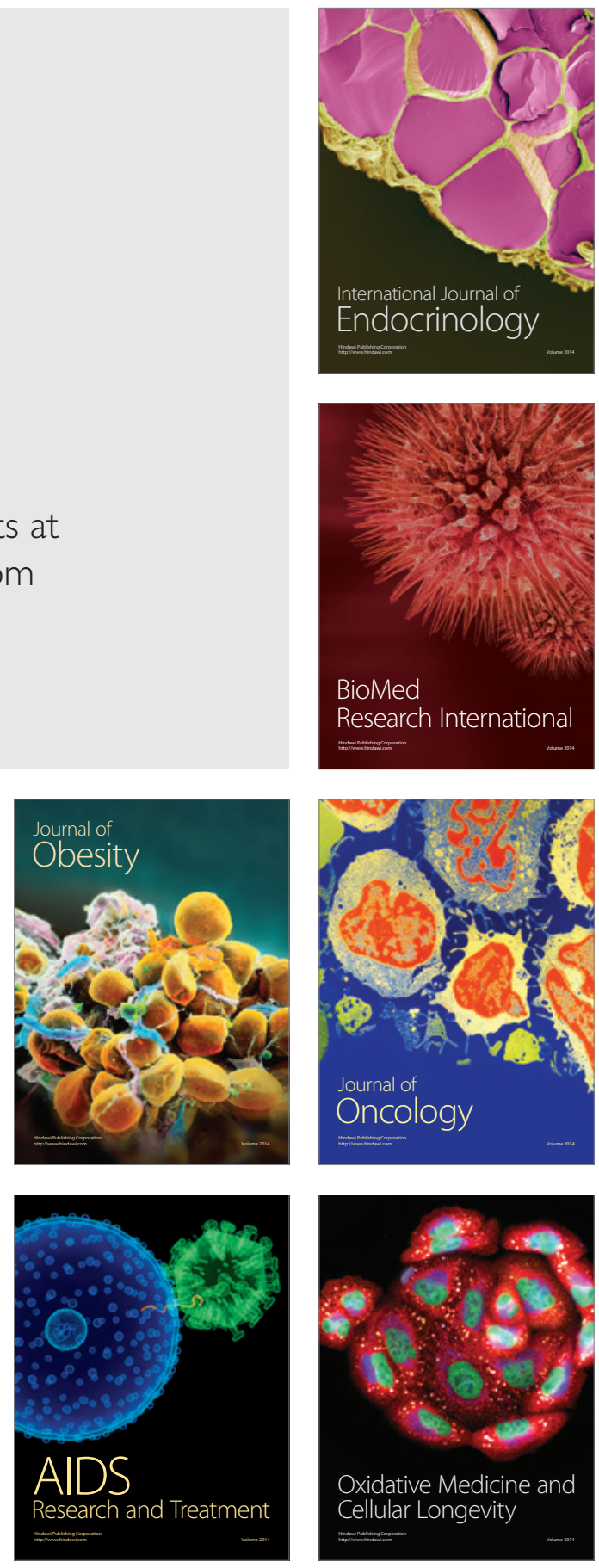